\title{
Plasma Potential and Langmuir Probe Measurements in the Near-field Plume of the NASA 300M Hall Thruster
}

Abstract: In order to aid in the design of high-power Hall thrusters and provide experimental validation for existing modeling efforts, plasma potential and Langmuir probe measurements were performed in the near-field plume of the NASA 300M Hall thruster. A probe array consisting of a Faraday probe, Langmuir probe, and emissive probe was used to interrogate the plume from approximately $0.1-2.0 \mathrm{DT}, \mathrm{m}$ downstream of the thruster exit plane at four operating conditions: $300 \mathrm{~V}, 400 \mathrm{~V}$, and $500 \mathrm{~V}$ at $20 \mathrm{~kW}$ as well as $300 \mathrm{~V}$ at 10 $\mathrm{kW}$. Results show that the acceleration zone and high-temperature region were contained within 0.3 DT,m from the exit plane at all operating conditions. Isothermal lines were shown to strongly follow magnetic field lines in the nearfield, with maximum temperatures ranging from $19-27 \mathrm{eV}$. The electron temperature spatial distribution created large drops in measured floating potentials in front of the magnetic pole surfaces where the plasma density was small, which suggests strong sheaths at these surfaces. The data taken have provided valuable information for future design and modeling validation, and complements ongoing internal measurement efforts on the NASA 300M. 
Plasm a Potential and Langmum Probe Mea rements in the Nearefield Plume of NASA-300M Hall Thruster

Daniel A. Herman (presenter), Rohit Shastry, Wensheng Huang, George C. Soulas, and Hani Kamhawi NASA Glenn Research Center, Cleveland, OH, 44135

Companion papers : AIAA-2012-4196, AIAA-2012-3870, AIAA-2012-3940

The $48^{\text {th }}$ AIAA/ASME/SAE/ASEE Joint Propulsion Conference and Exhibit July 31, 2012 


\section{Presentation Outline}

- Background and motivation

- Experimental setup

- Test article - the NASA-300M

- Electrostatic probe setup

- Test results - Contours of plasma potential and electron temperature

- Discussion of results

- Isothermal line structure

- Effects of isothermal lines on plasma near magnetic pole surfaces

- Analysis of the acceleration zone/high-temperature regions

- Check of azimuthal symmetry

- Conclusions 


\section{Background \& Motivation}

- There has been increased interest in higher-power Hall thrusters in the $20-50 \mathrm{~kW}$ range

- NASA Exploration Architectures

- SEP Technology Demonstration Mission

- The 20-kW NASA-300M, designed \& built at GRC, is a good candidate for high-power Hall studies

- Characterize performance/efficiency for future high-power Hall thruster designs

- Implement long-life magnetic shielding

- Provide baseline data on existing test article for comparison to design involving magnetic shielding

- Provide experimental data for validation of ongoing modeling efforts at JPL/GRC using Hall2De

- Part of this effort is electrostatic probe measurements taken in the near-field plume
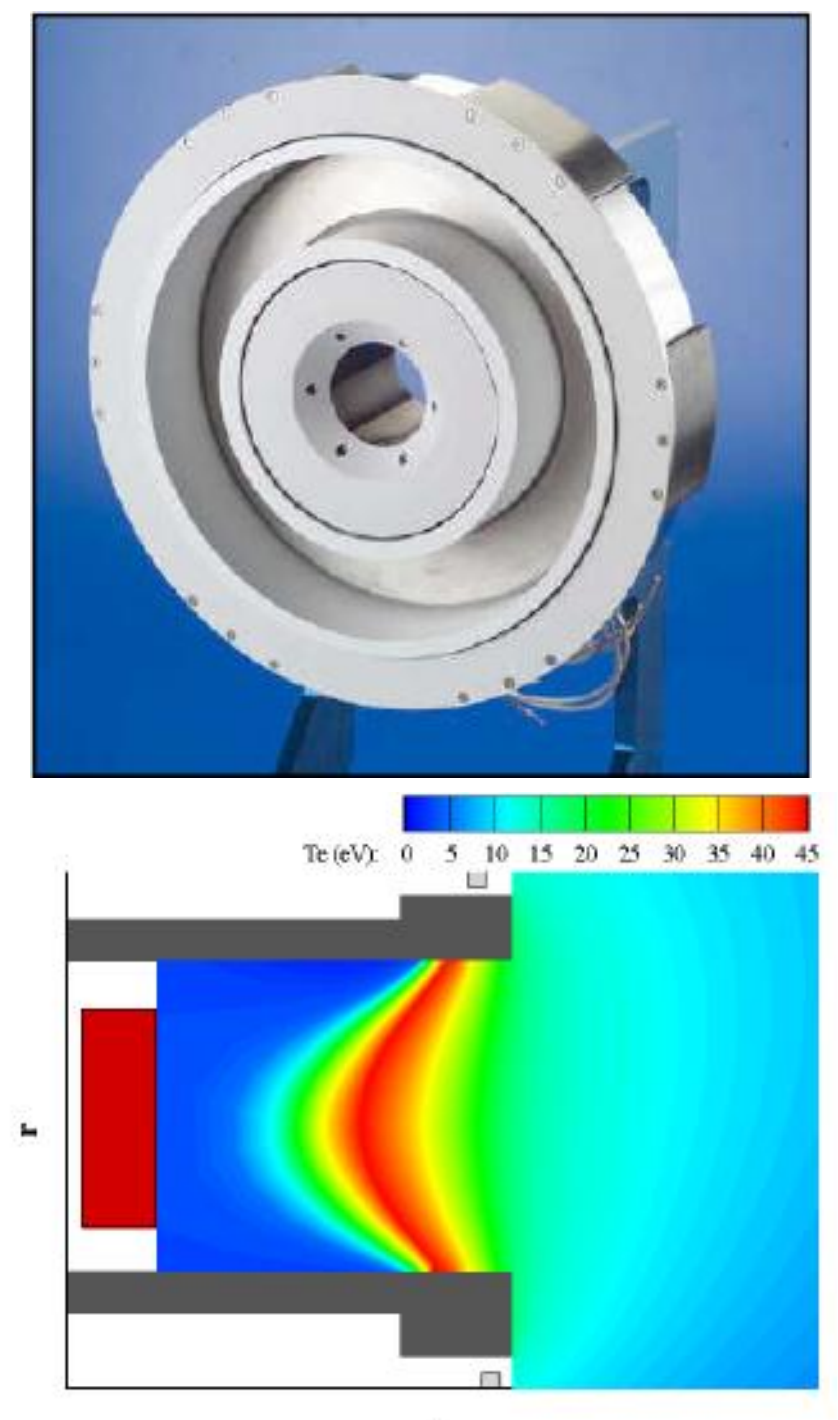

z

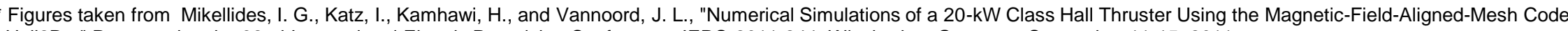
Hall2De," Presented at the 32nd International Electric Propulsion Conference, IEPC-2011-244, Wiesbaden, Germany, September 11-15, 2011. 


\section{Experimental Setup - NASA-300M}

- Test article is 20-kW NASA-300M Hall thruster, typically operated up to $500 \mathrm{~V}$ discharge voltage as well as $67 \mathrm{~A}$ discharge current

- Thruster placed in main volume of Vacuum Facility 5 at NASA GRC

- Commercial power supplies used to sustain discharge and supply power to magnets and cathode heater/keeper

- Center-mounted cathode made flush with thruster exit plane to enable nearfield measurements

- Symmetric magnetic field topology selected with strength that maximizes anode efficiency as measured by thrust stand 


\section{Electrostatic Probe Setup - General}

- Electrostatic probe rake comprised of near-field Faraday probe, Langmuir probe, and two emissive probes (one redundant)

- Probes swept in radial direction $\pm 4 \mathrm{D}_{\mathrm{T}, \mathrm{m}}$ about thruster centerline, at various axial locations downstream of thruster chosen to have fine spatial resolution close to thruster, with increasing steps as probes move farther away

- Probes run at approximately $250-375 \mathrm{~mm} / \mathrm{s}$ in radial direction to minimize residence time in front of thruster
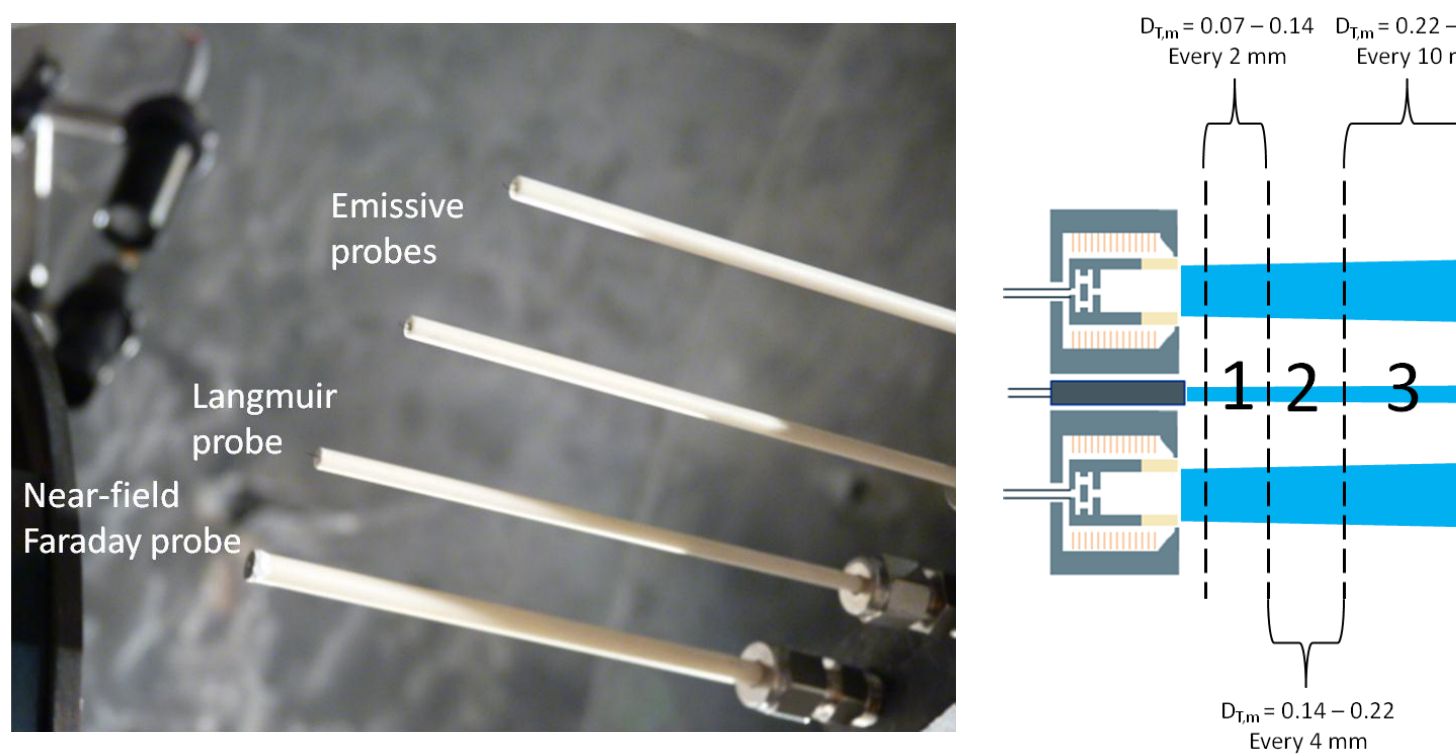

$\mathrm{D}_{\mathrm{T}, \mathrm{m}}=1.0-2.0$ Every $50 \mathrm{~mm}$ 


\section{Electrostatic Probe Setup - Langmuir Probe}

- Langmuir probe made of pure tungsten wire $0.250 \mathrm{~mm}$ in diameter and $2 \mathrm{~mm}$ long

- Encapsulated "null" probe isolated from plasma to characterize line capacitance currents to be subtracted out in post processing

- Currents measured across $160-\Omega$ carbon resistors, voltage measured using voltage divider

- All signals isolated from data acquisition system using voltage-following isolation amplifiers

- Probes swept from -85 to $+15 \mathrm{~V}$ using 125 $\mathrm{Hz}$ triangle wave, with $75 \mathrm{kHz}$ sampling rate - results in 300-pt I-V characteristics approximately every $\mathrm{mm}$ in radial direction

- Data analysis largely follows simple Langmuir probe theory
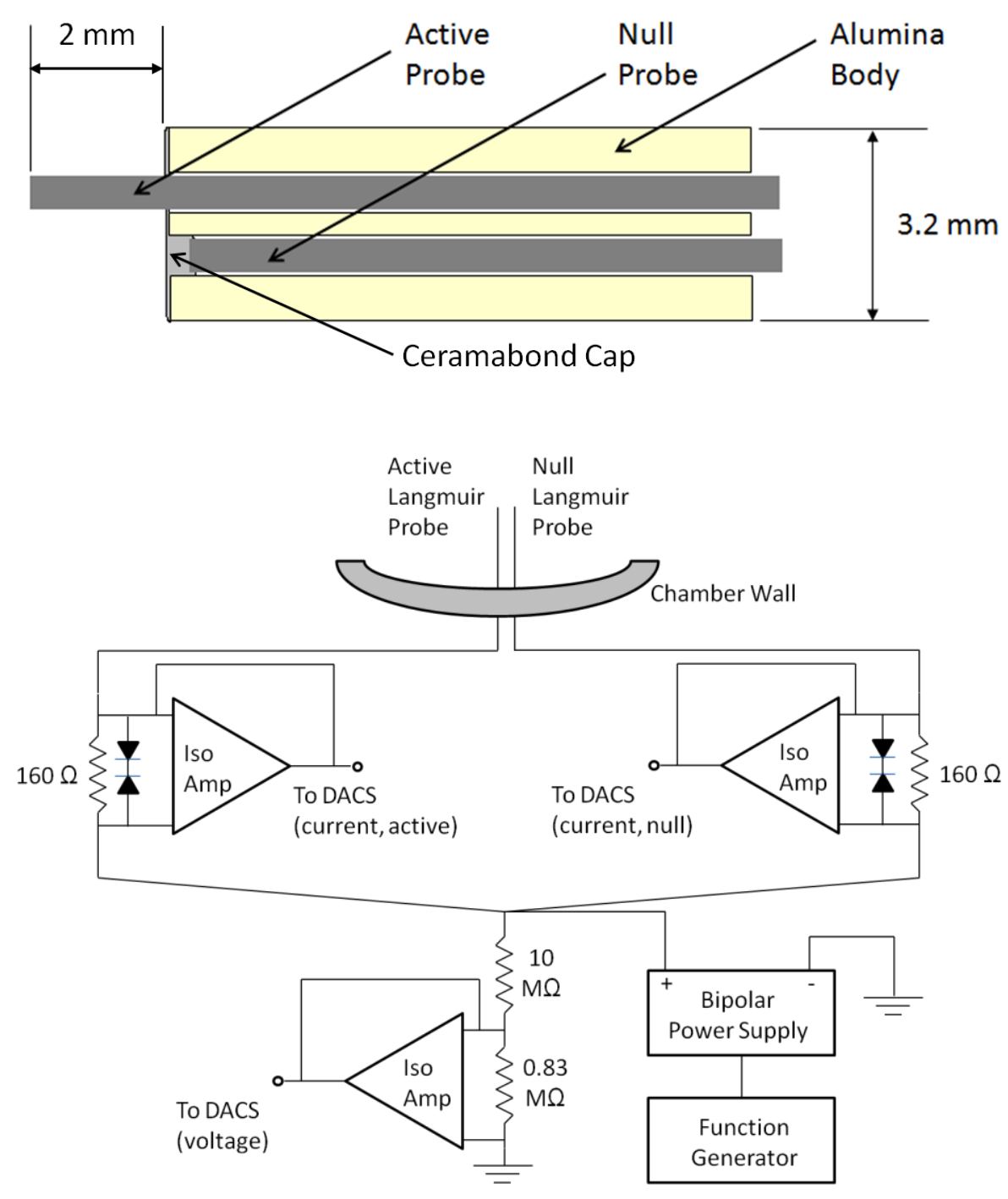


\section{Electrostatic Probe Setup - Emissive Probe}

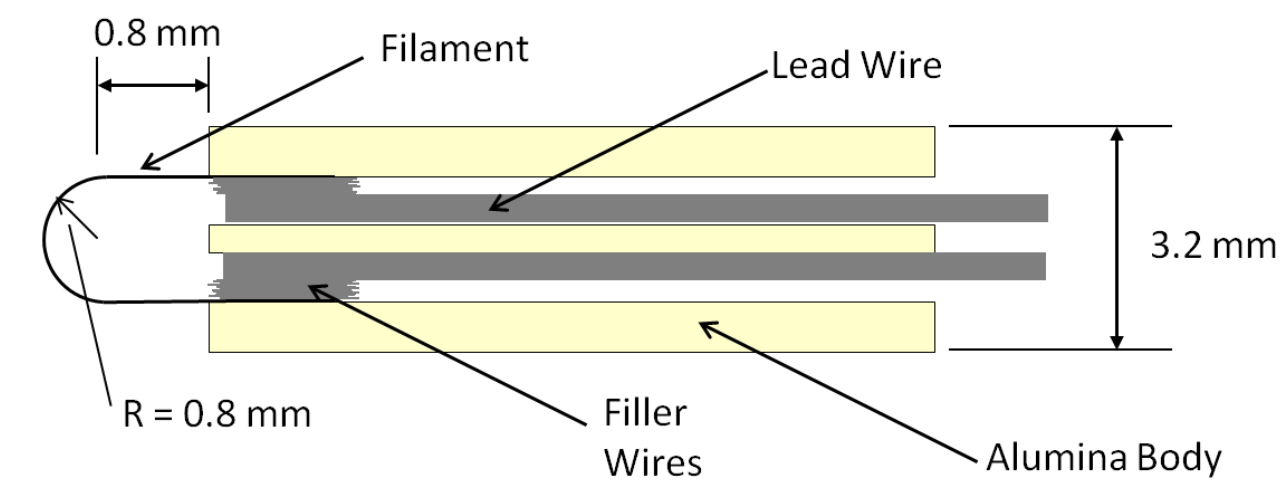

- Emissive probe filament comprised of 0.102-mm-diameter $1 \%$ thoriated tungsten wire bent into loop with radius of curvature of $0.8 \mathrm{~mm}$

- Pure tungsten wire used for lead wires and "filler" wires to provide tight fit between filament and lead wires

- Floating power supply provided necessary current to heat up filament

- Potential measured on each side of filament and averaged in post-processing

- Each radial sweep downsampled to 2000 points to provide approximately $1 \mathrm{~mm}$ spatial resolution 


\section{Test Results - Plasma Potential at 500 V, 20 kW}

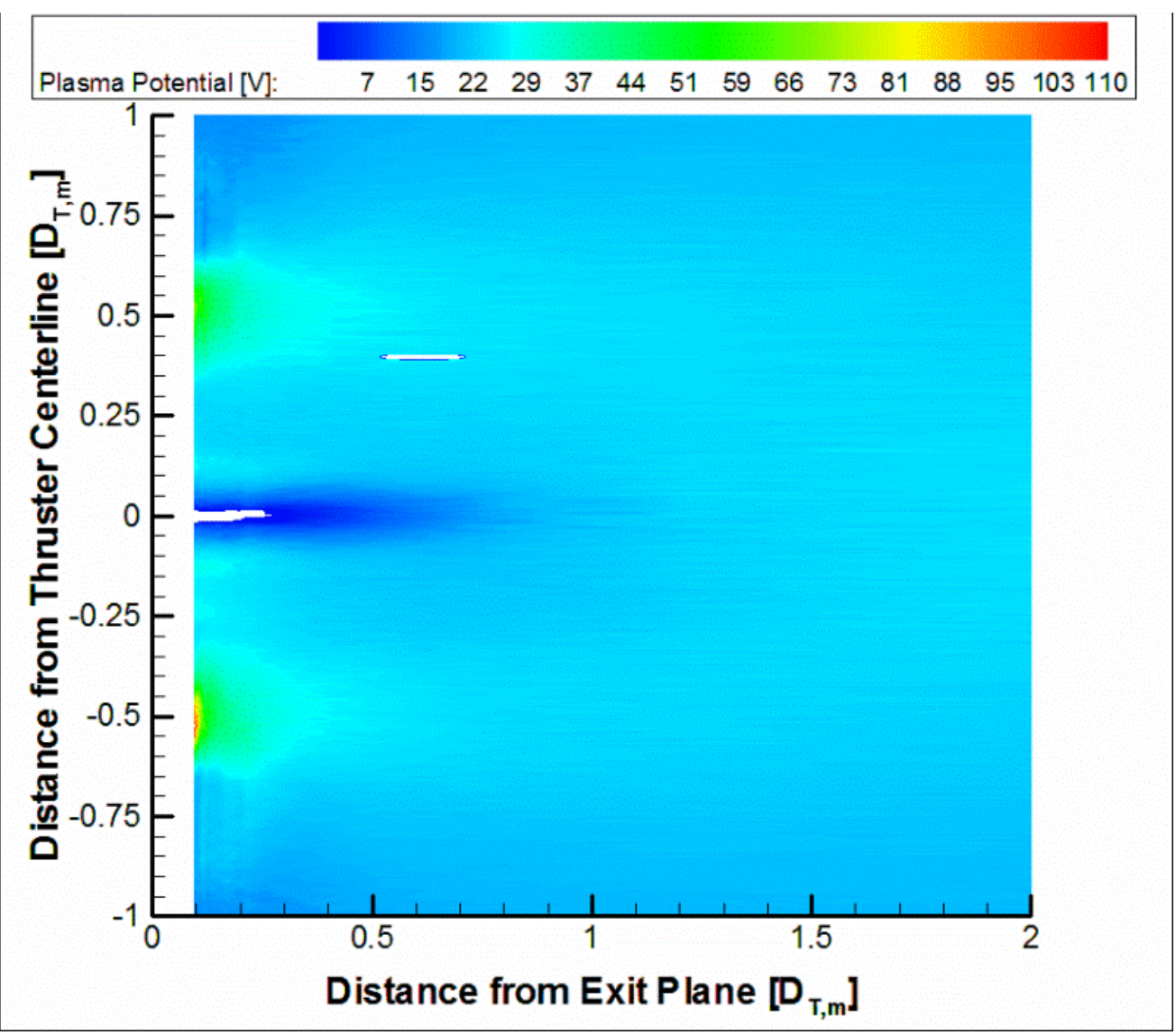

- Nominal condition was deemed critical for modeling effort, used both emissive probes to collect data as close to thruster as possible

- Most of near-field plume is $20-30$ $\mathrm{V}$ above cathode potential

- Acceleration zone limited to 0.2 $\mathrm{D}_{\mathrm{T}, \mathrm{m}}$ from thruster exit plane

- Maximum measured potential is $96 \mathrm{~V}$ above cathode potential 


\section{Test Results - Electron Temperature Contours}
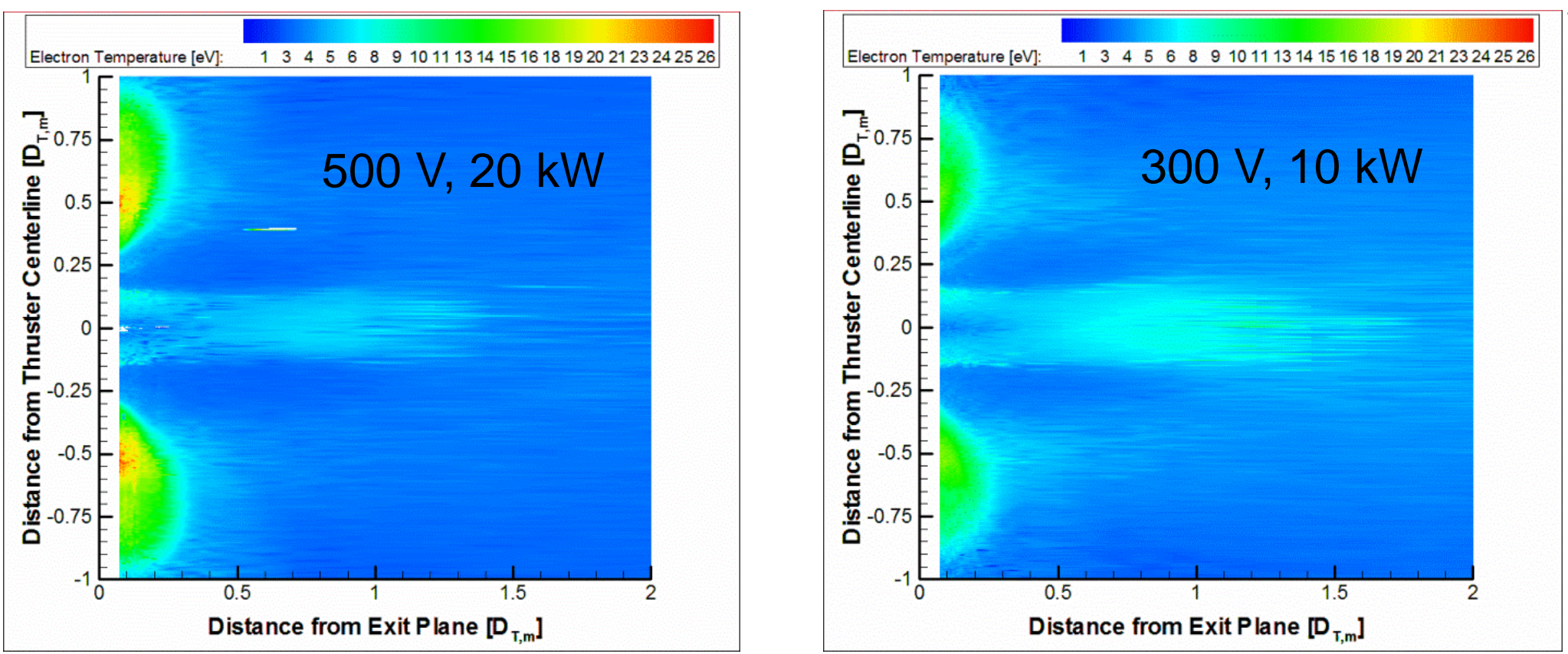

- Similar isothermal structure seen across all four operating conditions presented in paper $(300,400,500 \mathrm{~V}$ at $20 \mathrm{~kW}, 300 \mathrm{~V}$ at $10 \mathrm{~kW})$

- Near-field plume is at constant electron temperature of $2-5 \mathrm{eV}$ beyond 0.3 $\mathrm{D}_{\mathrm{T}, \mathrm{m}}$

- Maximum measured electron temperatures vary from $19-27 \mathrm{eV}$ depending on operating condition 


\section{Isothermal Line Structure - Similar Across Operating Conditions?}

- Radial profiles of electron temperature $0.07 \mathrm{D}_{\mathrm{T}, \mathrm{m}}$ from the thruster exit plane shows similar structure across operating conditions

- Peak temperature seen close to channel centerline, with rapid dropoff towards thruster centerline and more gradual dropoff away from thruster centerline

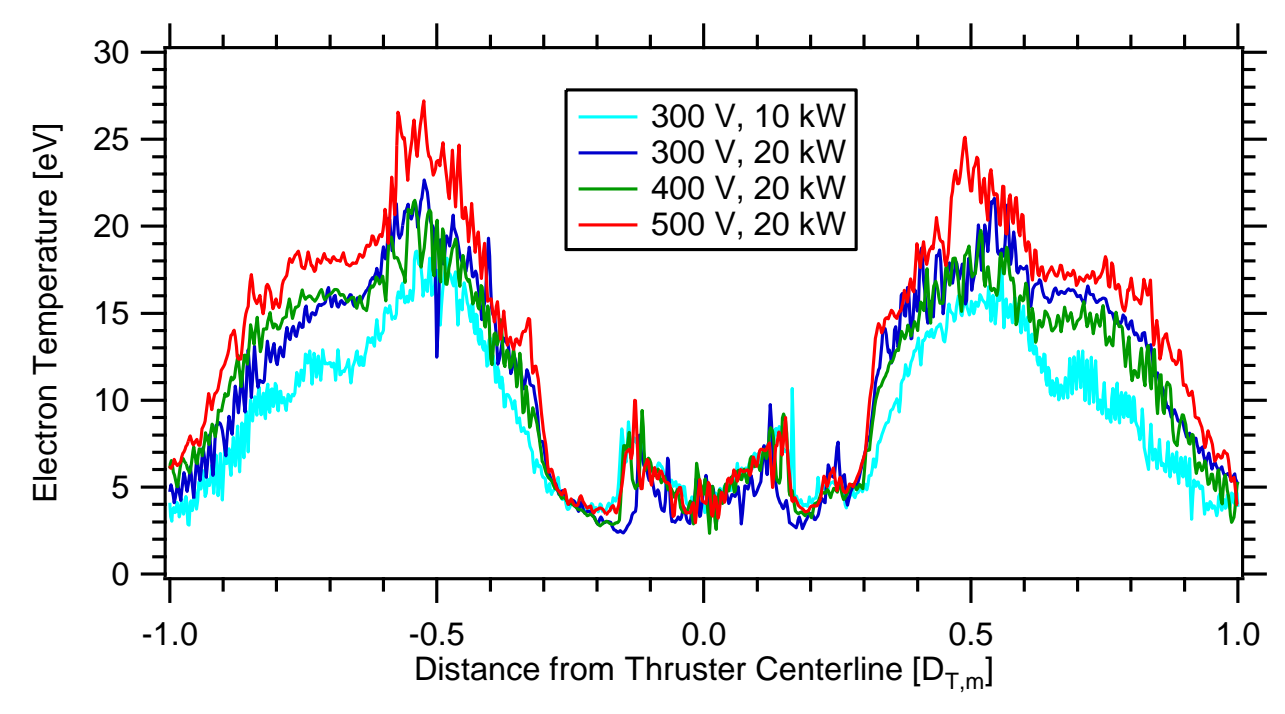




\section{Isothermal Line Structure - Similar Across Operating Conditions?}

- Radial profiles of electron temperature $0.07 \mathrm{D}_{\mathrm{T}, \mathrm{m}}$ from the thruster exit plane shows similar structure across operating conditions

- Peak temperature seen close to channel centerline, with rapid dropoff towards thruster centerline and more gradual dropoff away from thruster centerline

- Non-dimensionalizing each profile by the maximum temperature shows a near universal shape across operating conditions
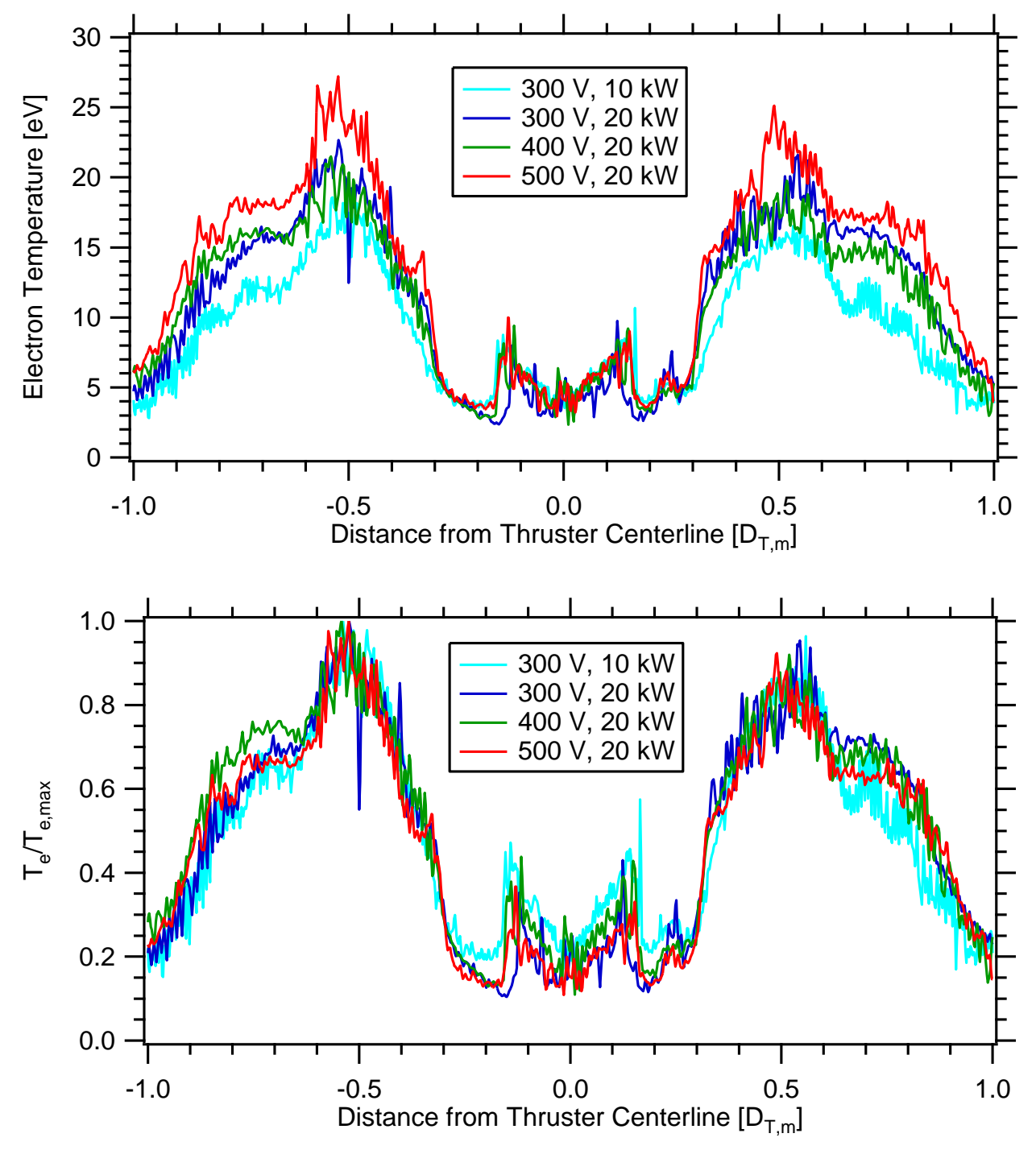


\section{Isothermal Line Structure - Driven by Magnetic Field Shape}
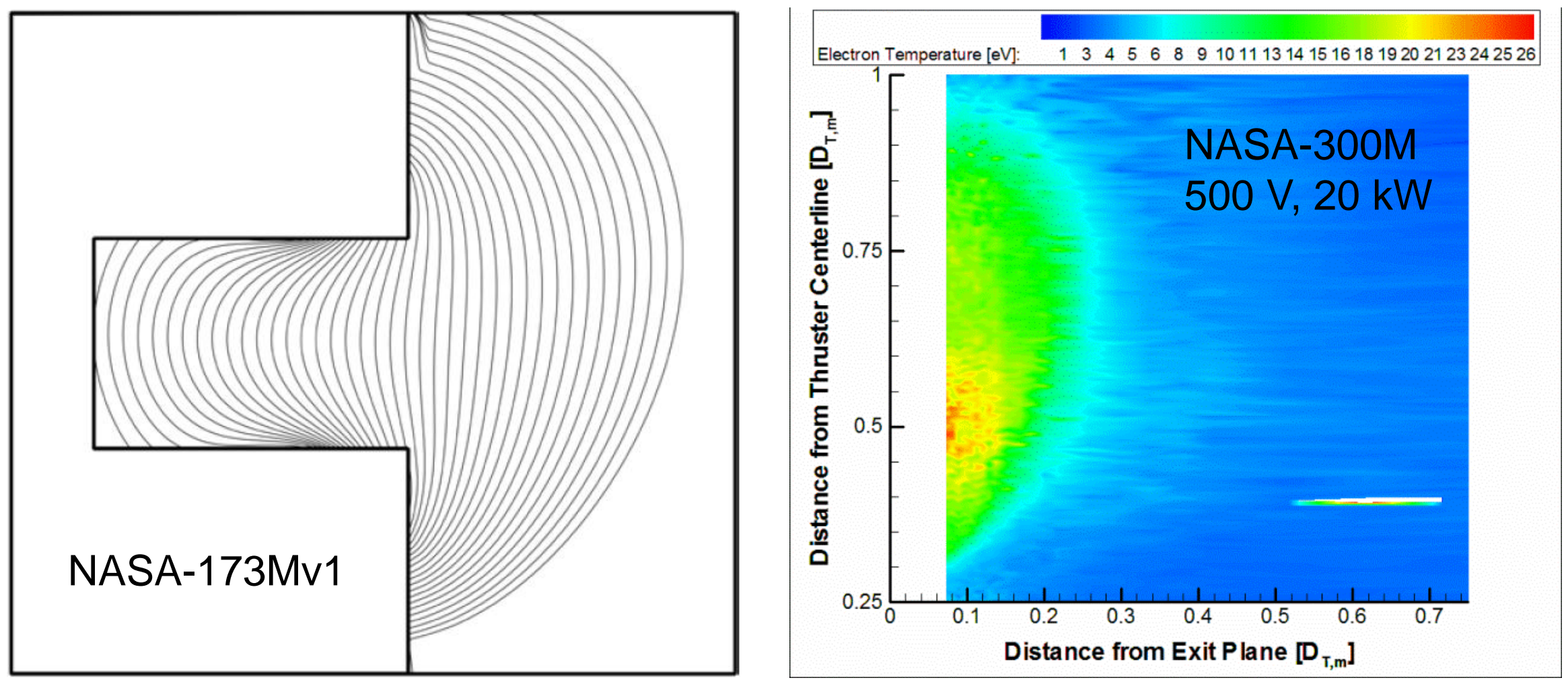

- Comparing the isothermal lines to a typical magnetic field topology in the near-field shows similarity in structure indicating that magnetic field lines indeed shape the isothermal lines in the near-field plume

- Universal shape across operating conditions consistent with fixed shape of magnetic field topology during study 


\section{Isothermal Line Structure - Affects Floating Potentials Near Magnetic Pole Surfaces}
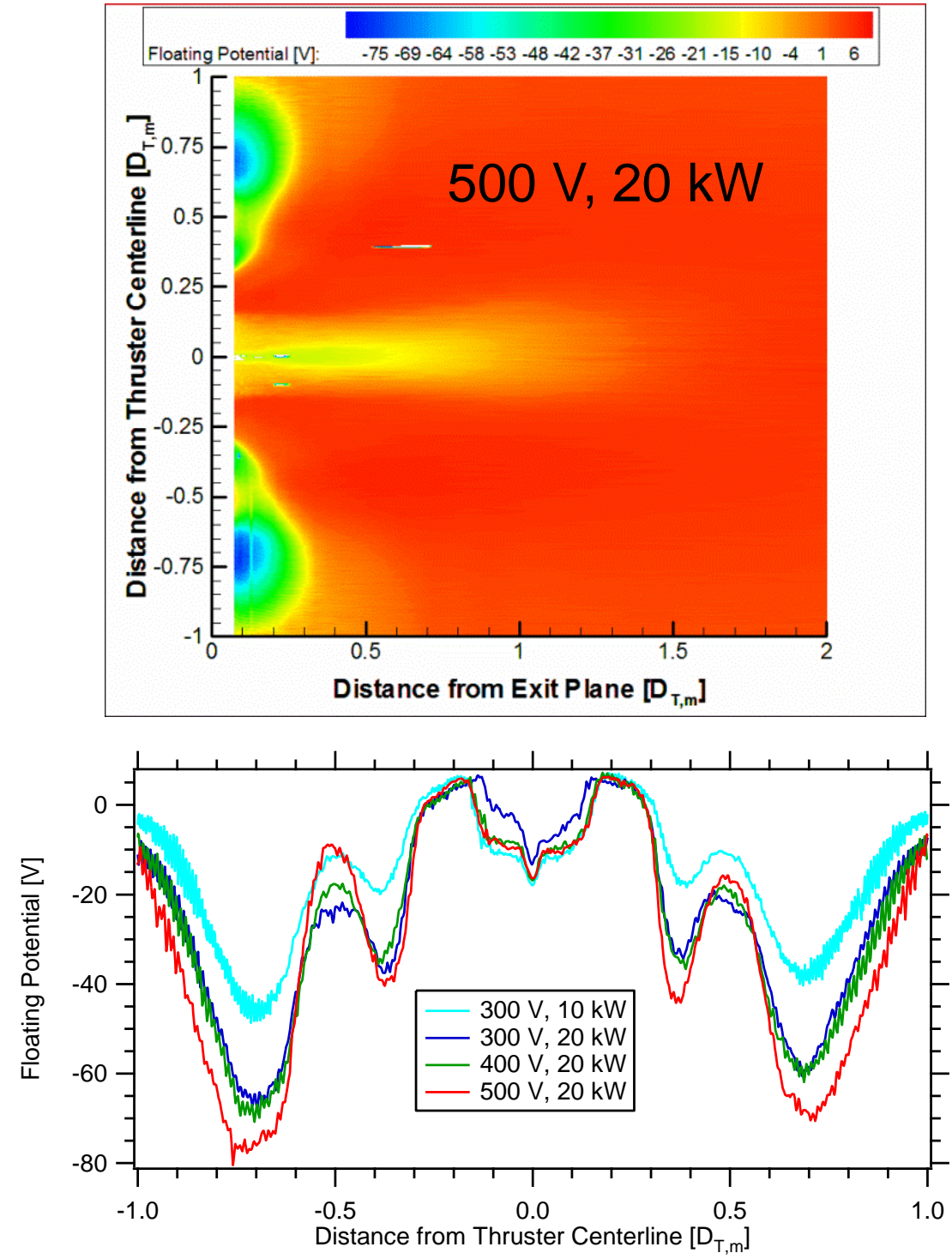

- Low floating potentials approaching $80 \mathrm{~V}$ below facility ground observed in regions surrounding channel bounds

- Is the result of isothermal line structure drawing high electron temperatures from downstream of the channel to regions of low plasma potential and number density

- Effect is more pronounced at higher voltages where higher temperatures are seen in plume, and on outer side of channel where high-temperature region is wider

- Expect thick, perhaps strong sheaths at magnetic poles

- Need to account for this effect for proper ion saturation measurements in these regions 


\section{Acceleration Zone/High-temperature Region In the Near-field Plume}

- Axial profiles along channel centerline show rapid increase in plasma potential and electron temperature as exit plane is approached

- At $500 \mathrm{~V}, 20 \mathrm{~kW}$, only $\sim 20 \%$ of the potential rise towards anode has been captured

- Average electron heating at $500 \mathrm{~V}, 20$ $\mathrm{kW}$ is $0.25 \mathrm{eV} / \mathrm{V}$ of potential, which is higher than previously reported values in other thrusters $(0.07-0.16 \mathrm{eV} / \mathrm{V})$

- Could point to increased electron heating in near-field plume of $300 \mathrm{M}$, but more data in the acceleration zone is needed to confirm this result
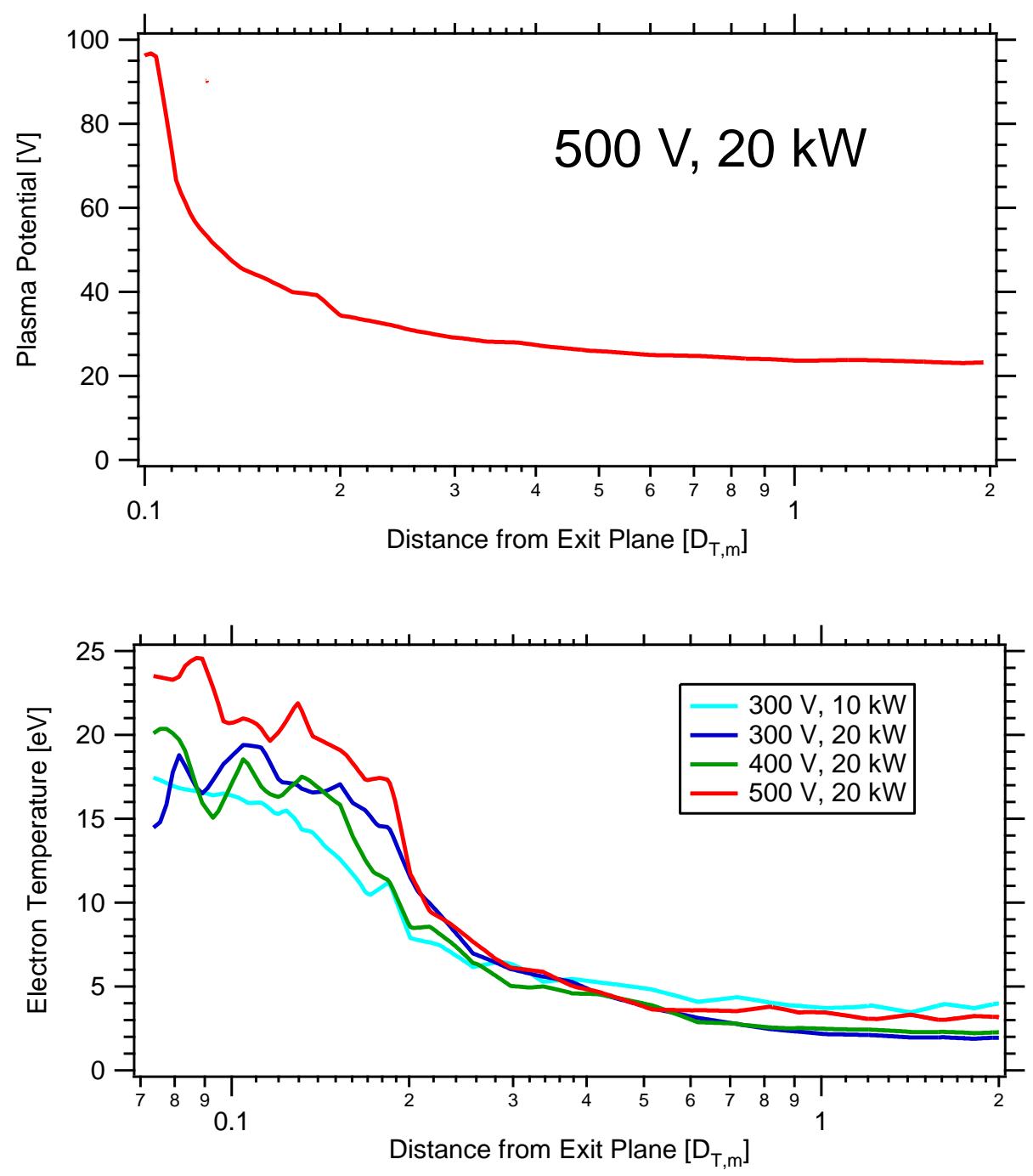


\section{Check of Azimuthal Symmetry between Clocked Positions}
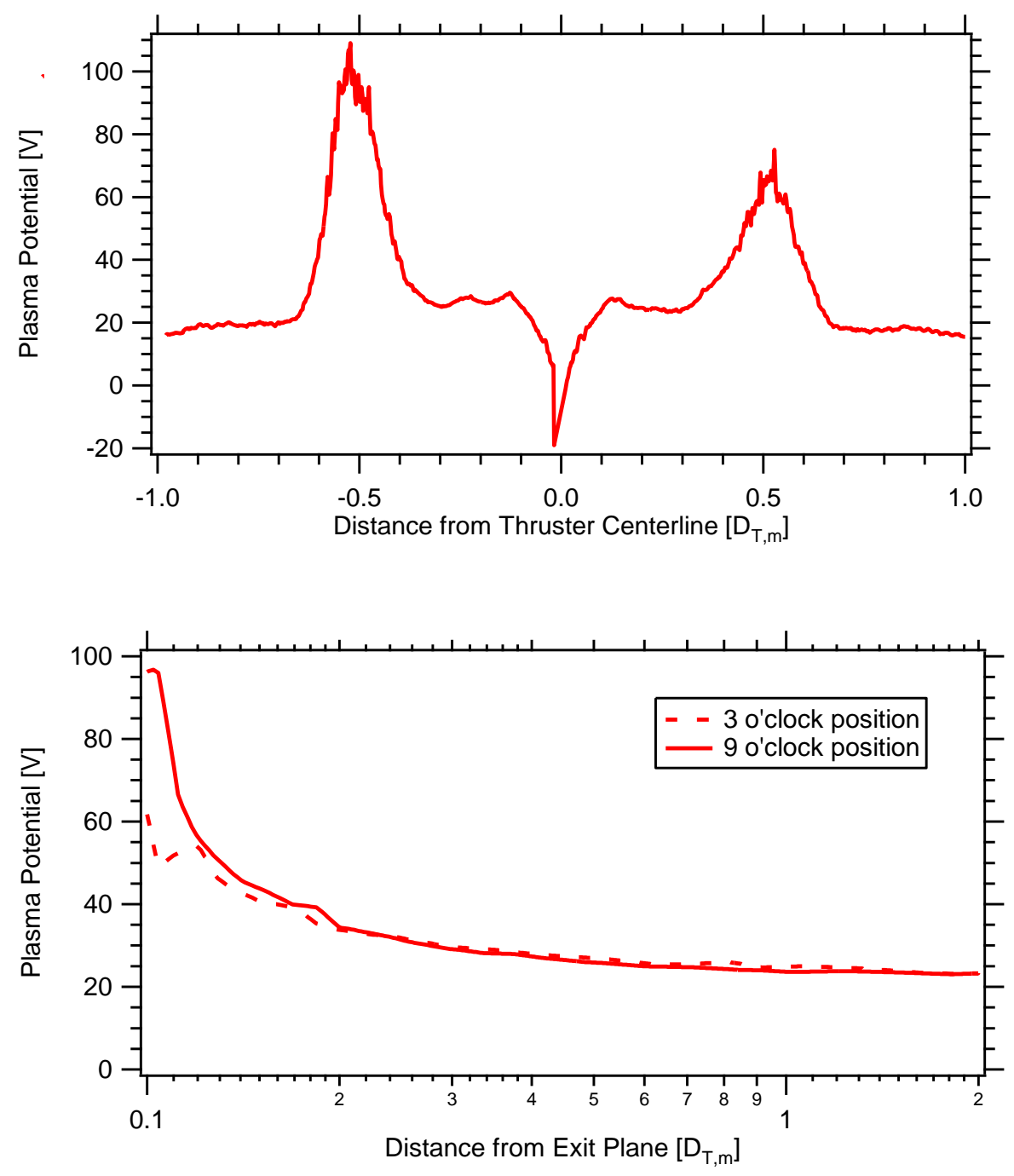

- Due to interrogation method, data from 3 o'clock and 9 o'clock positions can be compared to check azimuthal symmetry

- Plasma potential data at $500 \mathrm{~V}, 20 \mathrm{~kW}$ shows asymmetry due to a slight shift in acceleration zone

- This shift of $\sim 0.01 \mathrm{D}_{\mathrm{T}, \mathrm{m}}$ could be due to a slight table misalignment $(\sim 0.75$ degrees)

- Thruster appears to be symmetric to within the uncertainty of the table alignment with the thruster exit plane 


\section{Conclusions}

- With renewed NASA interest in 20-50 kW Hall thrusters, an electrostatic probe array was used to interrogate the near-field plume of the 20-kW NASA-300M

- Data shows that the acceleration zone and high-temperature regions are limited to $0.3 \mathrm{D}_{\mathrm{T}, \mathrm{m}}$ from the thruster exit plane

- A near-universal structure of isothermal lines was found across operating conditions that appears to be shaped by the magnetic field topology

- This isothermal line structure results in very low measured floating potentials near the magnetic pole surfaces adjacent to the channel bounds

- Analysis of the acceleration zone indicates there may be enhanced electron heating in the near-field plume

- Comparison of the two interrogated clocked positions indicates azimuthal symmetry to within the alignment uncertainty of the motion table

- The data taken in this study is valuable for modeling efforts and for comparison to ongoing internal measurements on the NASA-300M 
Questions? 